\title{
Deforming arthropathy in systemic lupus erythematosus
}

\author{
A. S. RUSSELL, J. S. PERCY, W. M. RIGAL, AND G. L. WILSON \\ University of Alberta, Edmonton, Alberta, Canada
}

Arthritis is a well-recognized feature of systemic lupus erythematosus (SLE), which may be confused with the joint manifestations of rheumatoid arthritis (Tumulty, 1954). Two recent reviews of the articular disorders of SLE have emphasized that, apart from aseptic necrosis, destructive and deforming arthritis is rare in this disease (Pekin and Zwaifler, 1970; Labowitz and Schumacher, 1971). Arthritis without deformity has indeed been suggested as one of the preliminary American Rheumatism Association criteria for the diagnosis of SLE (Cohen, Reynolds, Franklin, Kulka, Ropes, Shulman, and Wallace, 1971).

\section{Material}

Seven of thirty patients with spontaneous SLE seen consecutively in the Rheumatic Disease Unit of the University of Alberta had a progressively deforming arthritis in the hands. All exhibited features of lupus that fitted the preliminary American Rheumatism Association criteria (Table) and in two (Cases 5 and 4) the diagnosis was confirmed at autopsy. The characteristic features of the joint deformities were that initially they could be voluntarily corrected, often by 'trick' movements, even when marked subluxation was present. Furthermore, they were not associated with radiologically detectable erosions.

In four of the patients described $(4,1,2,5)$ direct inspection at surgery confirmed that there was no macroscopic damage to the cartilage in the involved joints, and in two of these ( 4 and 5 ) further confirmation was obtained at autopsy some months later. The clinical features of the disease in these seven patients are shown in the Table. We have endeavoured to use some of the categories and designations suggested in the preliminary American Rheumatism Association criteria, although like others (Fries and Siegel, 1973) we find these unsatisfactory in some respects.

Table Particulars of seven female patients

\begin{tabular}{|c|c|c|c|c|c|c|c|}
\hline Patient no. & 1 & 2 & 3 & 4 & 5 & 6 & 7 \\
\hline Age (yrs) & 25 & 39 & 51 & 47 & 52 & 41 & 21 \\
\hline Duration of disease (yrs) & 6 & 17 & 15 & 8 & 13 & 10 & 5 \\
\hline $\begin{array}{l}\text { Duration of joint deformity } \\
\text { (yrs) }\end{array}$ & 1 & 3 & 4 & 4 & 2 & 3 & 2 \\
\hline Steroid therapy & + & + & + & + & + & + & + \\
\hline Facial erythema (butterfly) & + & $\stackrel{T}{-}$ & 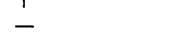 & + & + & + & + \\
\hline Raynaud's phenomenon & + & + & + & + & + & + & - \\
\hline Alopecia & + & - & + & + & unk. & + & + \\
\hline Photosensitivity & + & - & - & - & unk. & - & - \\
\hline $\begin{array}{l}\text { Pleuritis and/or pericarditis } \\
\text { Leucopenia, haemolysis, }\end{array}$ & $\overline{+}+\mathrm{L}$ & $\begin{array}{l}++ \\
+\mathrm{L}\end{array}$ & $\overline{+} \mathrm{H}, \mathrm{L}$ & $\overline{+} \mathbf{L}$ & unk. & $\begin{array}{l}+\mathrm{pl} \\
+\mathrm{L}\end{array}$ & $\begin{array}{l}+ \\
+\mathrm{L}, \mathrm{H}\end{array}$ \\
\hline LE cell factor & + & + & + & + & + & + & + \\
\hline Antinuclear antibody & + & + & + & + & + & + & + \\
\hline $\begin{array}{l}\text { Latex test for rheumatoid } \\
\text { factor }\end{array}$ & - & - & - & + & - & - & + \\
\hline Proteinuria $(3 \cdot 5 \mathrm{~g} . / 24 \mathrm{hrs})$ & - & - & + & + & + & + & + \\
\hline Cellular casts in urine & - & & - & + & - & - & + \\
\hline $\begin{array}{l}\text { Immunofluorescence of normal } \\
\text { skin }\end{array}$ & $1+$ & + & ND & - & + & - & ND \\
\hline $\begin{array}{l}\text { Glomerular histology } \\
\text { Keratoconjunctivitis sicca }\end{array}$ & $\begin{array}{l}\text { ND } \\
+\end{array}$ & $\begin{array}{l}\text { ND } \\
+\end{array}$ & $\begin{array}{l}\text { ND } \\
\text { tve Schirmer }\end{array}$ & $\begin{array}{l}\text { Prolif. GN } \\
\text { ND }\end{array}$ & $\begin{array}{l}\text { Mem. GN } \\
\text { ND }\end{array}$ & $\begin{array}{l}\text { Mem. GN } \\
+\end{array}$ & $\begin{array}{l}\text { Mem. GN } \\
\text { +ve Schirmer }\end{array}$ \\
\hline
\end{tabular}




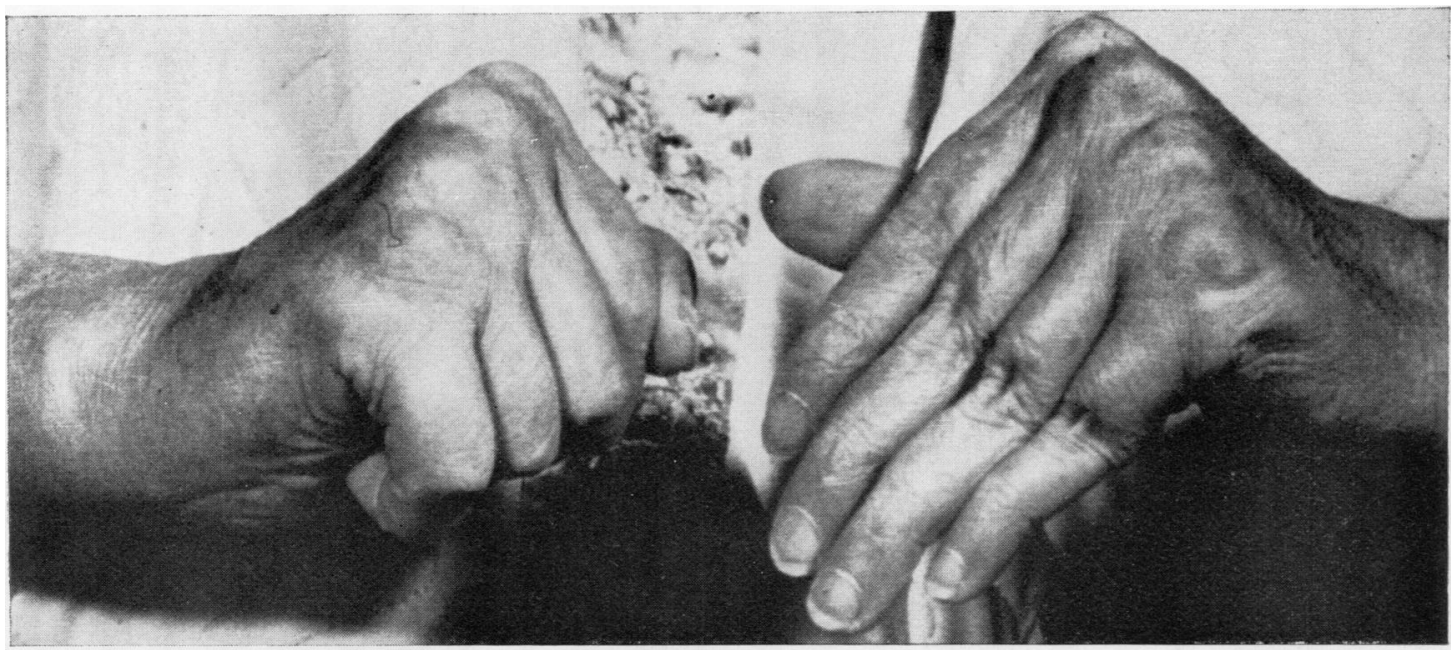

FIG. 1 Case 4. Correctable swan-neck deformities and ulnar deviation

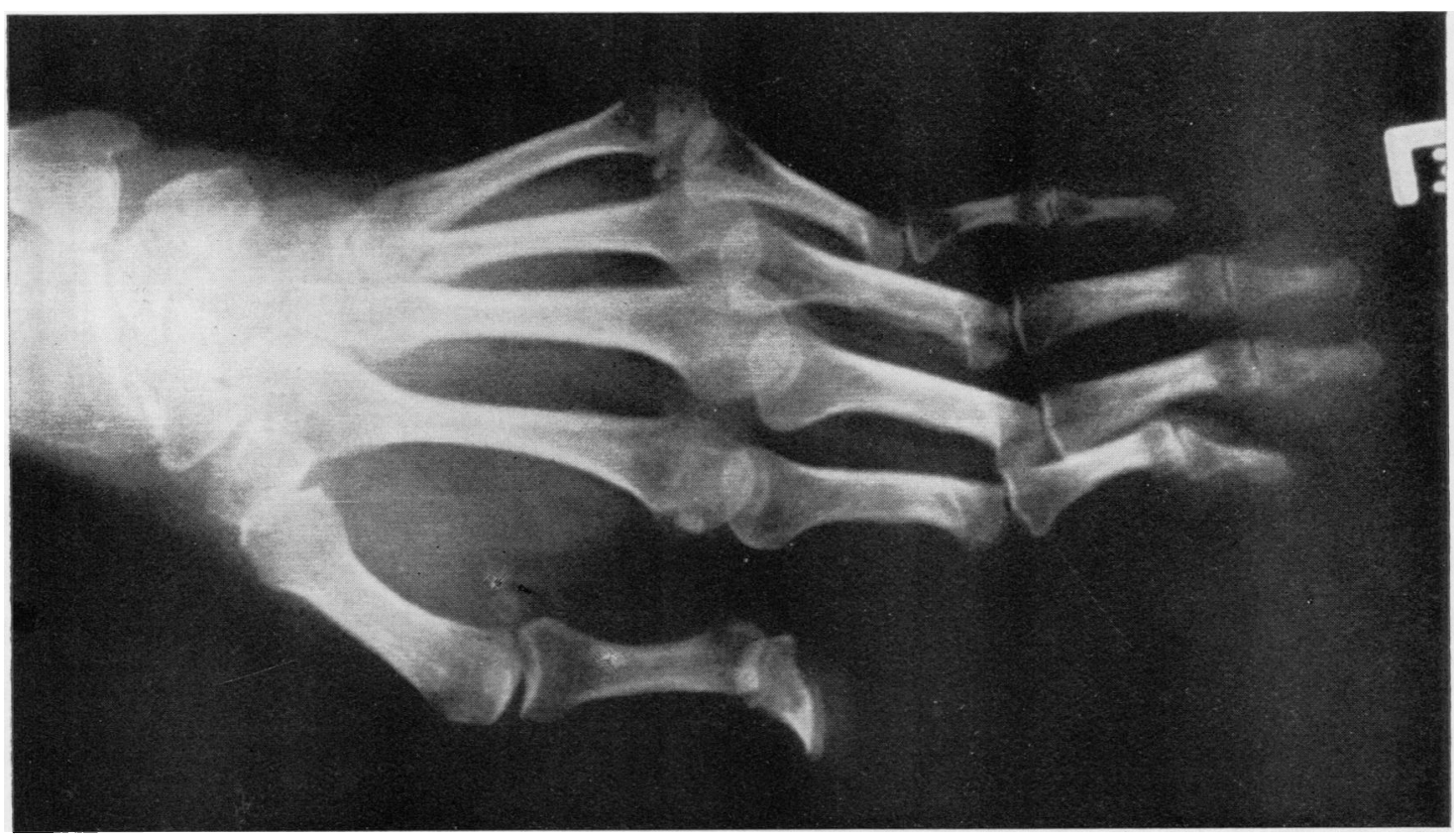

FIG. 2 Case 4. No evidence of bone erosion in spite of marked deformity

\section{HAND DEFORMITIES}

\section{Case 4}

Marked palmar subluxation of the proximal phalanges was present with moderate ulnar deviation. All the fingers had swan-neck deformities and an intrinsic plus deformity was noted in the thumb (Figs 1 and 2). The long extensor tendons were dislocated to the ulnar side of the metacarpophalangeal (MCP) joint. $X$ rays (Fig. 2) showed no evidence of bone damage and inspection of the MCP joints at operation did not reveal any cartilage erosions (Fig. 3, overleaf). The synovial membrane showed little infiltration with in flammatory cells (Fig. 4, overleaf).

\section{Case 2}

Bilateral palmar subluxation with pronounced ulnar deviation was present at the MCP joints of all fingers. Synovectomies were performed on these joints and the extensor tendons were relocated radially. At operation the articular cartilage appeared to be entirely normal. Prominent synovial hyperplasia was evident on histological examination but only mild mononuclear cell infiltration was seen. 
FIG. 3 Case 4. Metacarpal heads-no cartilage damage seen at operation

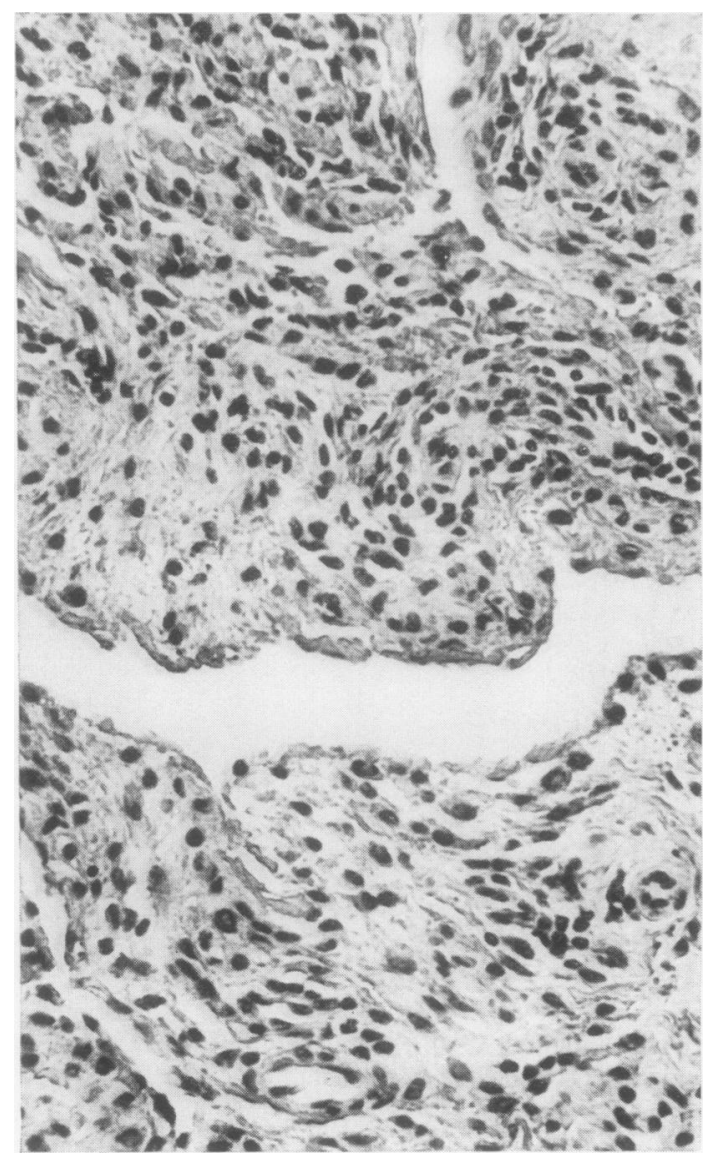

FIG. 4 Case 4. Synovia l membrane. $\times 200$

\section{Case 1}

Bilateral flexion contractures of the proximal interphalangeal (PIP) joints of all the fingers were present with hyperextension of the distal interphalangeal (DIP) joints (Fig. 5). None of these deformities was correctable by

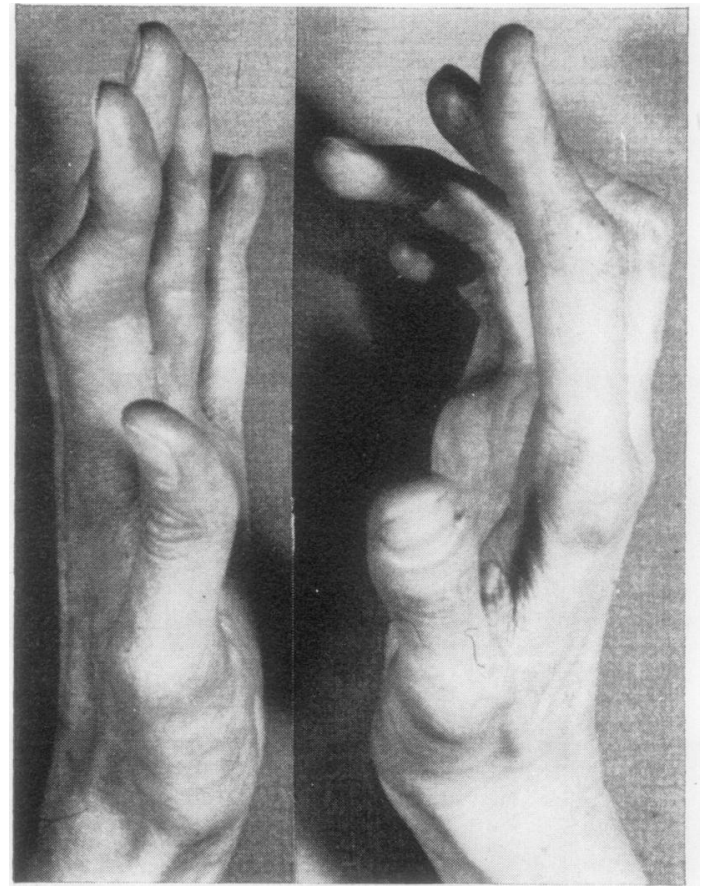

FIG. 5 Case 1. Non-correctable deformities of the PIP joints

active or passive movements. These abnormalities were found to be due to contractures of the ulnar wing tendons and the lateral retinacular ligaments. These were corrected surgically, and during the operation the middle slip of the extensor retinaculum was seen to be still firmly attached to its normal insertion in contrast to the usual boutonnière deformity of rheumatoid arthritis. The cartilage of the PIP joints was macroscopically entirely normal.

\section{Case 5}

Palmar subluxation and ulnar deviation of the proximal phalanges was present bilaterally and the extensor tendons were displaced to the ulnar side. All fingers showed swan-neck deformities. Replacement arthroplasties were performed on the MCP joints of the right hand. The articular cartilage was again seen to be normal.

\section{Case 6}

Correctable subluxation was present at the first carpometacarpal (CMC) joint. All fingers exhibited a triggering phenomenon because of dorsal subluxation of the proximal phalanges on the metacarpal heads. A fixed block to full extension of the PIP joints was present and was due to apparent contraction of the lateral retinacular ligament, as in Case 1.

\section{Case 7}

Mild ulnar deviation and palmar subluxation were present at the MCP joints of the fingers of the right hand (Fig. 6). There was also a flexion contracture of the fourth PIP joint. 


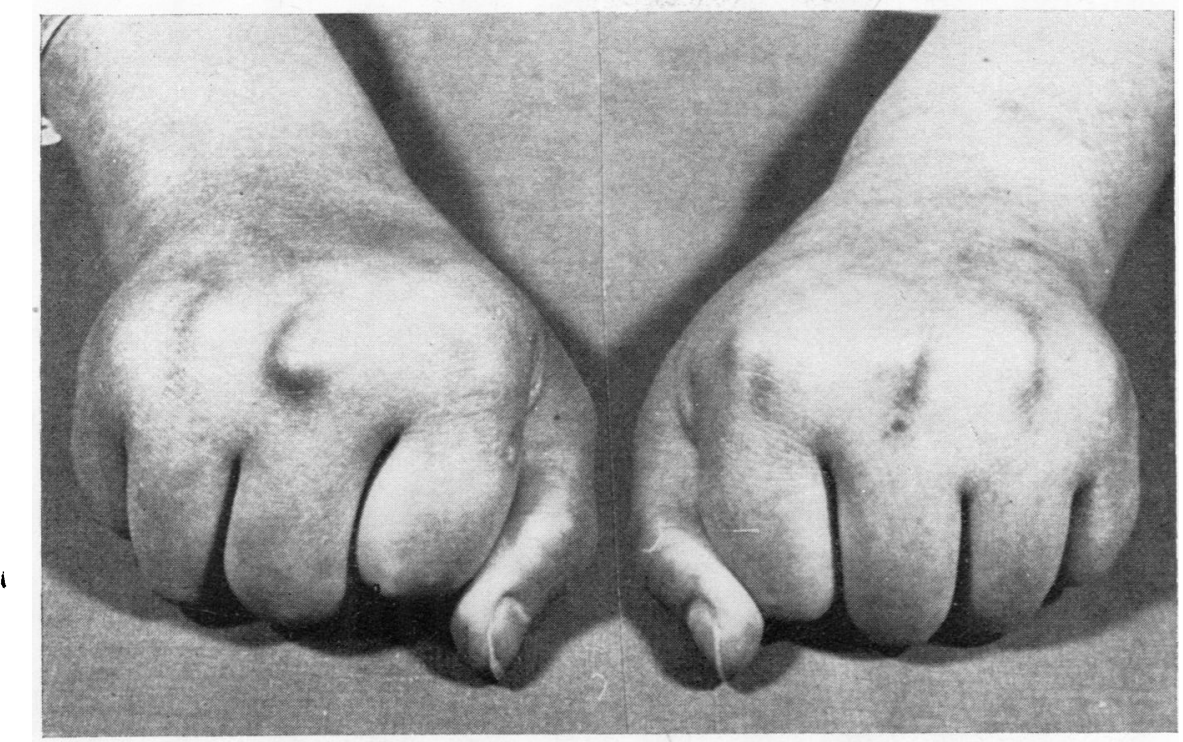

FIG. 6 Case 7. Mild ulnar deviation, especially on the right side

\section{Case 3}

All fingers showed correctable swan-neck deformities, but a mild fixed deformity of the distal IP joint of the right little finger had developed (Fig. 7, overleaf). Intermittent volar subluxation of the proximal phalanx of this finger was also present (Fig. 8, overleaf).

\section{Discussion}

Joint involvement occurs in about 90 per cent. of patients at some time during the course of systemic lupus erythematosus (Tumulty, 1954). Inflammation may not be prominent, and there is often a discrepancy between the severity of the subjective symptoms and the lack of objective changes. This paradox may even be a helpful indicator towards the correct diagnosis (Tumulty, 1954; Nesgovorova, 1966).

Although radiological evidence of bone erosions has been reported to occur in patients with SLE (Gould and Daves, 1955; Phocas, Andriotakis, Kaklamanis, and Antonopoulos, 1967), it is known to be rare, and indeed damage due to avascular necrosis is more frequent (Labowitz and Schumacher, 1971).

Noonan, Odone, Engleman, and Splitter (1963) described four patients out of a series of 25 with SLE who had joint deformities, and commented that two of them had a 'relative lack of severe bony erosions'. Our seven patients all had marked joint deformities, but none had detectable erosion of bone or cartilage.

In a recent review of the articular manifestations of SLE (Labowitz and Schumacher, 1971), two of 25 patients were noted to have swan-neck deformities in the hands, these were voluntarily correctable and were not associated with radiological evidence of damage to bone or cartilage. The rarity of erosive joint damage has also been commented on by other authors (Gould and Daves, 1955, Phocas and others, 1967; Cruickshank, 1959).

The deformities that we have described in the seven patients presented vary, but they have two characteristics in common: the absence of radiologically detectable erosions and, in all but one (Case 1), the correctable nature of the deformity. This is in marked contrast to rheumatoid arthritis where the appearance of hand deformity is paralleled by the radiological appearance of bony erosions. In addition, the hand deformities usually soon become permanent in rheumatoid arthritis, whereas the arthropathy of SLE appears to be similar to the Jaccoud's arthropathy of chronic rheumatic fever, where the deformities are also voluntarily correctable and are not associated with radiological evidence of joint damage (Bywaters, 1950; Zvaifler, 1962).

The arthritis of SLE is often evanescent and the synovial fluid demonstrates less evidence of inflammation than is seen in rheumatoid arthritis (Ropes and Bauer, 1953; Pekin and Zvaifler, 1970; Labowitz and Schumacher, 1971). The synovial membrane itself commonly shows only a mild degree of inflammation without marked synovial cell proliferation (Cruickshank, 1959). The development of deformity in our patients and in others previously described is clearly due to inflammation of and eventual contractures in para-articular tissues rather than damage to bone and cartilage.

The arthritis of SLE may be related to circulating 
immune complexes (Schur and Sandson, 1968), whereas that of rheumatoid arthritis is thought to be associated with a provocative factor localized inside the joint (Ziff, 1973). Furthermore, suggestive evidence of a role for cell-mediated immune joint damage in rheumatoid arthritis has been produced

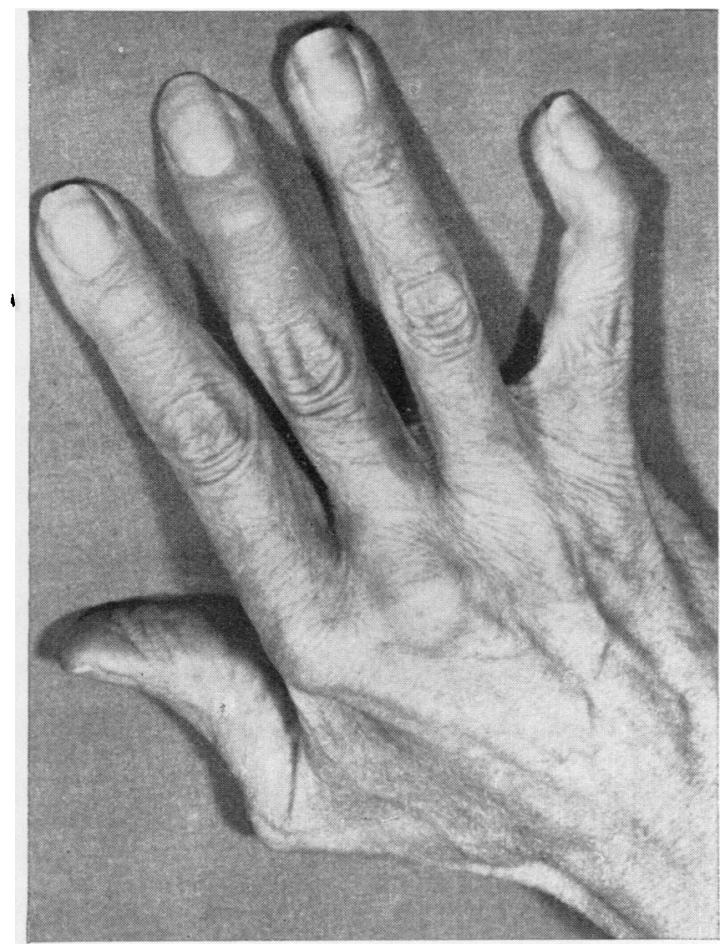

(Froland, Natvig, and Husby, 1973). These two factors may explain the contrast between the degree of cartilage destruction found in patients with rheumatoid arthritis when compared to those with SLE.

Because of the likelihood of case-referral selection, we cannot claim that our observation that almost 25 per cent. of patients with SLE have a characteristic deforming arthropathy represents the true incidence of permanent joint involvement in this disease. The low incidence of deforming arthritis cited by other authors may also be related to patterns of patient referral.

\section{Summary}

Arthritis is a common feature in patients with systemic lupus erythematosus, but the development of destruction or deformities in the affected joints is said to be rare. Indeed, the presence of a deforming arthritis has been specifically excluded as a criterion for the diagnosis of systemic lupus erythematosus by a recent committee of the American Rheumatism Association. We found a deforming but nondestructive arthritis in seven out of thirty patients with well-documented systemic lupus erythematosus. The characteristic feature of these deformities is that they are not associated with erosions, and this was confirmed during surgical exposure in four patients. Furthermore, the deformities could, in the early stages, be voluntarily corrected, often by 'trick' movements, even when marked subluxation was present. We suggest that this type of arthropathy is not an uncommon feature of otherwise classical systemic lupus erythematosus.

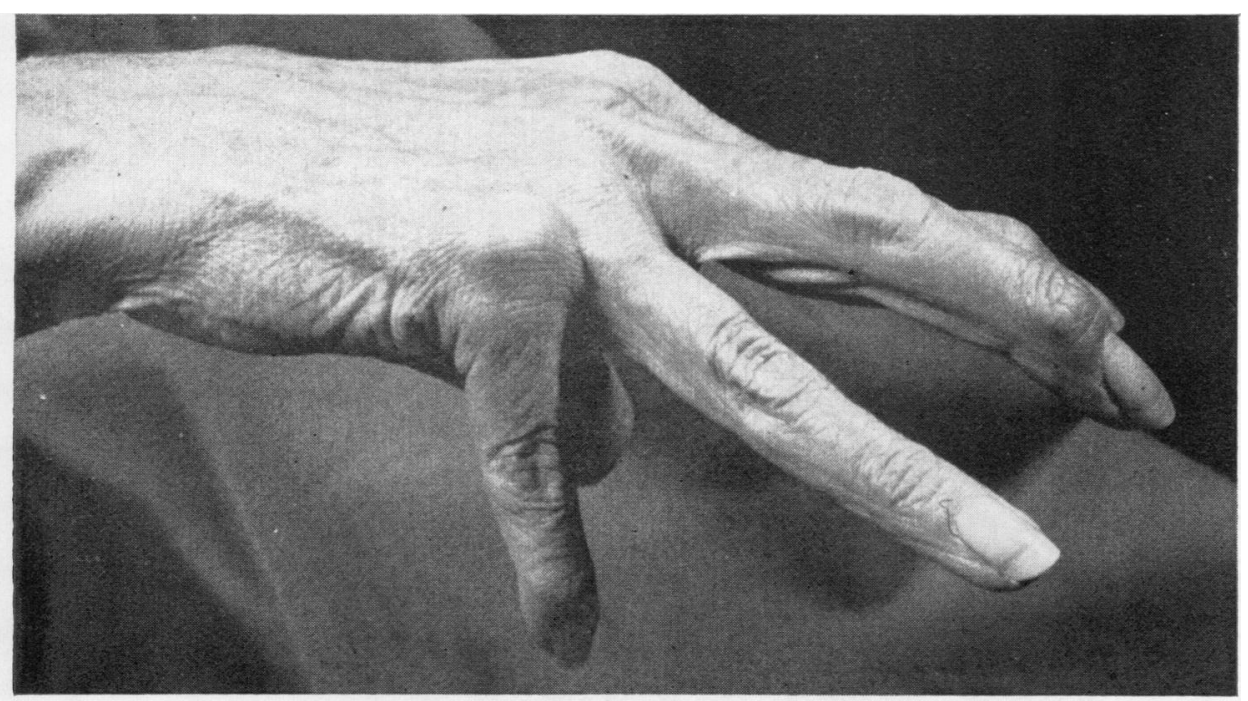




\section{References}

Bywaters, E. G. L. (1950) Brit. Heart J., 12, 101 (The relation between heart and joint disease including 'rheumatoid heart disease' and chronic post-rheumatic arthritis (type-Jaccoud))

Cohen, A. S., Reynolds, W. E., Franklin, E. C., Kulka, J. P., Ropes, M. W., Shulman, L. E., and Wallace, S. L. (1971) Bull. rheum. Dis., 21, 643 (Preliminary criteria for the classification of systemic lupus erythematosus)

Cruickshank, B. (1959) Ann. rheum. Dis., 18, 111 (Lesions of joints and tendon sheaths in systemic lupus erythematosus)

Fries, J. F., AND Siegel, R. C. (1973) Ibid., 32, 171 (Testing the 'preliminary criteria for classification of systemic lupus erythematosus')

Froland, S. S., Natvig, J. B., ANd Husby, G. (1973) Scand. J. Immunol., 2, 67 (Immunological characterization of lymphocytes in synovial fluid from patients with rheumatoid arthritis)

Gould, D. M., AND Daves, M. L. (1955) J. chron. Dis., 2, 136 (Roentgenologic findings in systemic lupus erythematosus)

Labowitz, R., and Schumacher, H. R., JR. (1971) Ann. intern. Med., 74, 911 (Articular manifestations of systemic lupus erythematosus)

NeSGOVOROVA, L. I. (1966) Rheumatism, 22, 99 (Lupus polyarthritis)

Noonan, C. D., Odone, D. T., Engleman, E. P., And Splitter, S. D. (1963) Radiology, 80, 837 (Roentgenographic manifestations of joint disease in systemic lupus erythematosus)

Pekin, T. J., AND Zvaifler, N. J. (1970) Arthr. and Rheum., 13, 777 (Synovial fluid findings in systemic lupus erythematosus)

Phocas, E., Andriotakis, C., Kaklamanis, P., and Antonopoulos, M. (1967) Acta rheum. scand., 13, 137 (Joint involvement in systemic lupus erythematos and scleroderma (systemic sclerosis))

Ropes, M. W., AND BAUER, W. (1953) 'Synovial Fluid Changes in Joint Disease'. Harvard University Press, Cambridge, Mass.

Schur, P. H., AND SANDson, J. (1968) New Engl. J. Med., 278, 533 (Immunologic factors and clinical activity in systemic lupus erythematosus)

Tumulty, P. A. (1954) J. Amer. med. Ass., 156, 947 (The clinical course of systemic lupus erythematosus)

ZifF, M. (1973) Ann. rheum. Dis., 32, 131 (Pathophysiology of rheumatoid arthritis)

ZvaifLer, N. J. (1962) New Engl.J. Me0., 267, 10 (Chronic postrheumatic-fever (Jaccoud's) arthritis) 